\title{
Assay of empagliflozin tablets by a stability-indicating micellar electrokinetic chromatography method and cytotoxicity study of degraded samples
}

\author{
Pauline Trindade Biscaino'; Ana Paula Christ ${ }^{1}$; \\ Daniele Rubert Nogueira Librelotto'; Clarice Madalena Bueno Rolim'; \\ Andréa Inês Horn Adams ${ }^{\circledR 1^{*}}$ \\ ${ }^{1}$ Pharmaceutical Sciences Graduate Program, Federal University \\ of Santa Maria, Santa Maria, RS, Brazil
}

\begin{abstract}
The first method by micellar electrokinetic chromatography (MEKC) for the determination of empagliflozin in tablets was developed and validated following the ICH guidelines. The separation was achieved in a fused silica capillary with $50 \mu \mathrm{m}$ x $40 \mathrm{~cm}$ (inner diameter x effective length) at $28{ }^{\circ} \mathrm{C},+28 \mathrm{kV}$ voltage, hydrodynamic injection $4 \mathrm{~s}(50 \mathrm{mBar})$, detection at $225 \mathrm{~nm}$ and paracetamol was the internal standard. The running electrolyte was a mixture of $20 \mathrm{mM}$ tris(hydroxymethyl) aminomethane ( $\mathrm{pH} \mathrm{10)}$ and $100 \mathrm{mM}$ sodium dodecyl sulphate (1:1). Specificity was evaluated by the stress testing and the method was specific, with no interference of the degradation product. Linearity was observed in the range of 50 to $150 \mu \mathrm{g} / \mathrm{mL}(\mathrm{r}=0.9999)$. The method showed adequate accuracy (recovery value $=100.60 \pm 0.60 \%$ ), precision (RSD values $<2 \%$ ) and robustness, which was evaluated by a full factorial design $2^{3}$. Drug degradation kinetics was evaluated in alkaline and acidic conditions and first-order kinetic was observed in both conditions. The cytotoxicity of sample solutions degraded by UVA and UVC radiation, alkaline and acid media were studied as well. A similar cellular viability profile was observed with a slight decrease only in samples degraded by UVC radiation and basic medium.
\end{abstract}

Keywords: Capillary electrophoresis. Empagliflozin. Validation. Cellular viability. Degradation kinetics.

\section{INTRODUCTION}

Empagliflozin (Figure 1) was approved by the FDA in 2014 for the treatment of diabetes mellitus type 2. This drug is a potent and selective inhibitor of sodium-glucose cotransporter 2 (SGLT-2), which is responsible for the glucose reabsorption through glomerular filtration in the kidneys. This way, as a common effect, empagliflozin reduces the renal absorption and decreases the renal threshold for glucose resulting in an increase in the glucose excretion. In addition, there is a reduction in hyperglycemia, weight and blood pressure (Jojima et al., 2016). In general, empagliflozin is a well-tolerated drug and most adverse effects are transient. Such effects are headache, polyuria,

\footnotetext{
*Correspondence: A. I. H. Adams. Universidade Federal de Santa Maria - UFSM. Av. Roraima, 1000. Prédio 26, sala 1106. CEP 97105-900, Santa Maria/RS, Brazil. E-mail: andrea.ih.adams@gmail.com
}

thirst with dehydration and hypotension, and urinary tract infection (Cersosimo, Herrera-Solis, Triplitt, 2014; Milech, Oliveira, Vencio, 2016).

Analytical methods for the determination of empagliflozin in raw material and/or tablets are described and include high performance liquid chromatography (HPLC) (Geetha et al., 2016; Ghany-Abdel et al., 2017; Padmaja, Veerabhadram, 2016; Shyamala et al., 2016), ultra-high performance liquid chromatography (UPLC) (Ayoub, 2015; Gopal, Sridhar, 2017; Padmaja, Veerabhadram, 2017), ultraviolet (UV) spectrophotometry (Ayoub, 2016; Padmaja, Veerabhadram, 2015; Ayoub, 2017) and liquid chromatography coupled to mass spectrometry (LC-MS/MS) (Ayoub, 2017).

Although many methods were developed, there are no current publications about the determination of empagliflozin API and tablets in pharmacopoeias and 
methods by capillary electrophoresis (CE) are not reported as well. Electrokinetic migration-based separation techniques, such as electrophoresis, have complemented chromatographic techniques, providing a further option for analytical instrumentation (Watson, 2005; Rizvi, Do, Saleh, 2011; Barden et al., 2013). This method has these advantages: it is a green method that generates extremely small volumes of waste considering other techniques; it uses a small volume of solvents what makes it cheaper; easy to operate and handle; fast separation and a capillary lower cost comparing to HPLC columns (Altria, Marsh, Griend, 2006; Barden et al., 2013).

CZE is the simplest CE separation mode, applicable to analysis of ionizable molecules, while MEKC is a $\mathrm{CE}$ mechanism of separation used for the separation of neutral and charged molecules (Hancu et al., 2013). In MEKC, ionic surfactants are added to the running electrolyte in concentrations that provide the formation of micelles forming a two-phase system (electrolyte and micelles) (Harstad et al., 2016).

This work aimed to develop the first stabilityindicating MEKC method to evaluate empagliflozin tablets. Preliminary studies regarding drug stability were also developed using radiation, temperature and oxidative, alkaline and acidic media. Besides, it was evaluated the cytotoxicity of solutions containing empagliflozin and the degradation products generated through forced degradation studies.
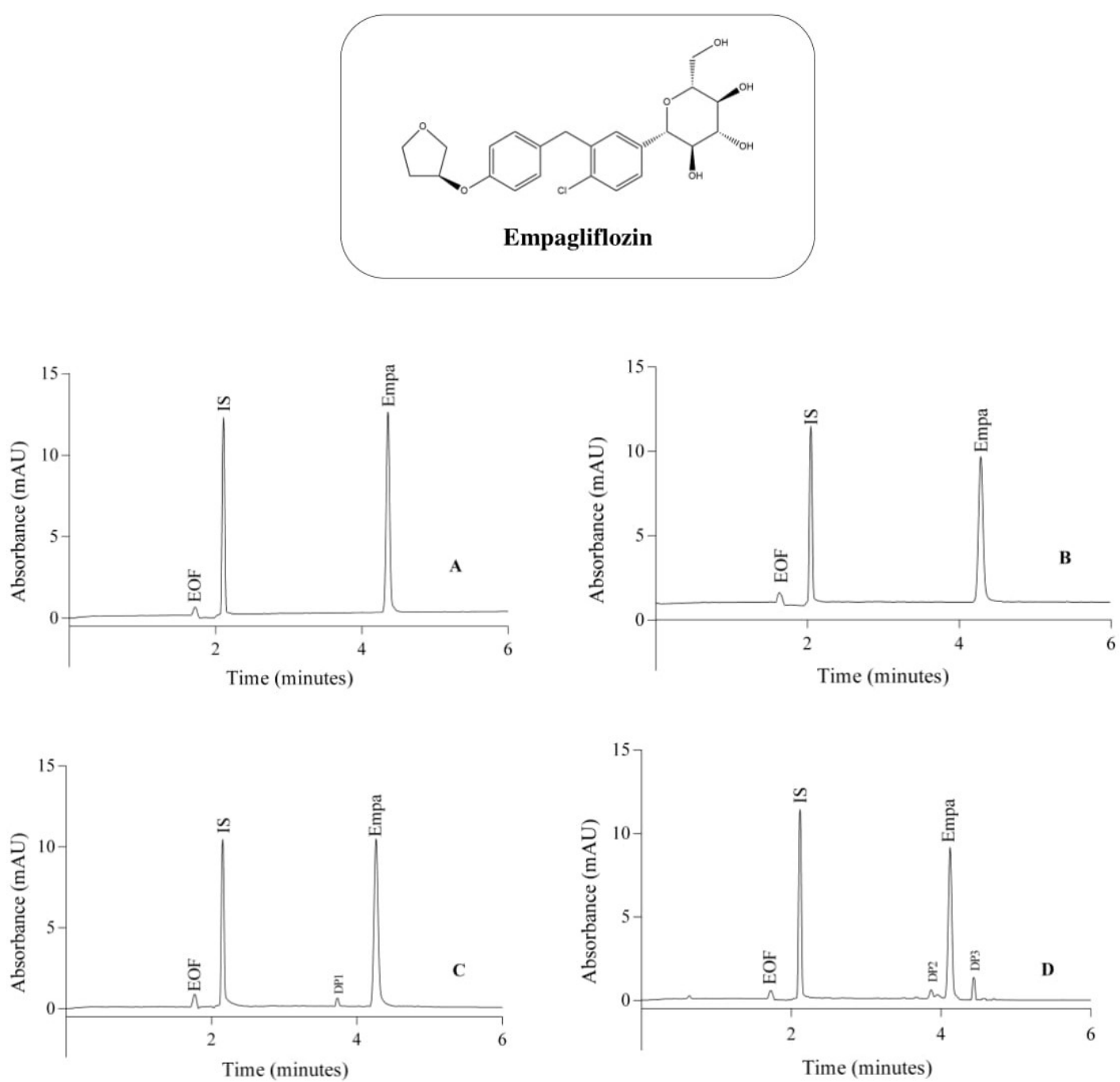

FIGURE 1 - Empagliflozin chemical structure and electropherograms from empagliflozin solutions exposed to stress testing. (A) empagliflozin standard solution. (B) non-degraded empagliflozin sample solution; (C) empagliflozin sample solution after exposure to UVA light (48 h); (D) empagliflozin sample solution after exposure to UVC light (5 h). EOF: eletroosmotic flow; IS: internal standard; DP1: degradation product 1; DP2: degradation product 2; DP3: degradation product 3. 


\section{MATERIAL AND METHODS}

\section{MEKC method development}

\section{Chemicals and reagents}

Empagliflozin standard (purity 99.77\%) was purchased from TripleBond Quality Standards (Ontario, Canada) and the paracetamol used as internal standard (IS) was purchased from Galena (São Paulo, Brazil). Jardiance ${ }^{\circledR}$ coated tablets containing $25 \mathrm{mg}$ of empagliflozin (Boehringer Ingelheim, Germany) were commercially obtained. Other reagents of reagent grade included: tris(hydroxymethyl)aminomethane (TRIS) (Proquímios, Rio de Janeiro, Brazil), sodium dodecyl sulfate (Neon, Suzano, Brazil), methanol and sodium hydroxide (Dinâmica Química Contemporânea, São Paulo, Brazil), hydrogen peroxide and hydrochloric acid (Vetec Química Fina, Rio de Janeiro, Brazil). Ultrapure water used in all analyses was obtained from a Milli-Q Gradient water purification system (Millipore Corp., Billerica, USA).

In the cytotoxicity study, dimethyl sulfoxide (DMSO), 3-(4,5-dimethylthiazol-2-yl)-2,5-diphenyltetrazolium bromide (MTT), phosphate buffered saline (PBS) and trypsin-EDTA solution $(170,000 \mathrm{U} / \mathrm{L}$ trypsin and $0.2 \mathrm{~g} / \mathrm{L}$ EDTA) were obtained from Sigma-Aldrich (St. Louis, USA). Fetal bovine serum (FBS) and Dulbecco's Modified Eagle's Medium (DMEM) with L-glutamine ( $584 \mathrm{mg} / \mathrm{L})$ and antibiotic/antimicotic $(50 \mathrm{mg} / \mathrm{mL}$ gentamicin sulfate and $2 \mathrm{mg} / \mathrm{L}$ amphotericin B) were purchased from Vitrocell (Campinas, Brazil).

\section{Instrumentation and analytical conditions}

Analyses were conducted on an Agilent $7100^{3 \mathrm{D}} \mathrm{CE}$ instrument (Agilent Technologies, Waldbronn, Germany) equipped with automatic sampler, photodiode detector and temperature controller. The CE ChemStation B.04.03 software was used for data acquisition and analysis.

MEKC analyses were carried out on a $48.5 \mathrm{~cm}$ uncoated fused silica capillary (NST-Nano Separation Technologies, São Carlos, Brazil) with $50 \mu \mathrm{m}$ x $40 \mathrm{~cm}$ (inner diameter $\mathrm{x}$ effective length), thermostatized at 28 ${ }^{\circ} \mathrm{C}$. New capillaries were conditioned for 15 minutes with $1 \mathrm{M} \mathrm{NaOH}$ plus 15 minutes in water. Before starting the experiments, the capillary was sequentially preconditioned for 15 minutes with $0.1 \mathrm{M} \mathrm{NaOH}$, water for 15 minutes and running electrolyte for 15 minutes. In addition, to obtain the migration time reproducibility, the capillary was conditioned among injections, with $0.1 \mathrm{M} \mathrm{NaOH}$ for 3 minutes, water for 4 minutes and buffer solution for 5 minutes. After the application of two injections, the running electrolyte was replaced by a new buffer solution to avoid changes in the electroosmotic flow (EOF) and subsequent variations in the area and migration time. The optimized conditions were: hydrodynamic injection of $50 \mathrm{mBar}$ for $4 \mathrm{~s}$; applied voltage $+28 \mathrm{kV}$; detection at $225 \mathrm{~nm}$ using diode array detector (PDA).

\section{Running electrolyte preparation}

The running electrolyte was a solution of $20 \mathrm{mM}$ TRIS buffer, $\mathrm{pH}$ 10: $100 \mathrm{mM}$ sodium dodecyl sulphate (SDS) $(1: 1 \mathrm{v} / \mathrm{v})$. Before the analysis, $\mathrm{pH}$ was adjusted to 10.0 at $25^{\circ} \mathrm{C}$ with $1 \mathrm{M}$ hydrochloric acid and the solution was filtered through a $0.45 \mu \mathrm{m}$ nylon filter (Sartorius Stedim Biotech, Germany).

\section{Standard and sample solutions preparation}

Empagliflozin standard solution was prepared by dilution in methanol to $1000 \mu \mathrm{g} / \mathrm{mL}$ and subsequent dilution in water to have $200 \mu \mathrm{g} / \mathrm{mL}$. The IS solution (paracetamol at $400 \mu \mathrm{g} / \mathrm{mL}$ ) was prepared in water. Then, both solutions were mixed in a 1:1 proportion. The final solution contained $100 \mu \mathrm{g} / \mathrm{mL}$ of empagliflozin and 200 $\mu \mathrm{g} / \mathrm{mL}$ of IS.

For the sample solution preparation, 20 tablets were weighed to verify the average weight and then they were ground. A quantity of powdered tablets equivalent to 10 $\mathrm{mg}$ of empagliflozin was transferred to $10 \mathrm{~mL}$ volumetric flasks. Approximately $5 \mathrm{~mL}$ of methanol were added to the solution followed by sonication for 10 minutes and, in sequence, the volume was adjusted with methanol obtaining a $1000 \mu \mathrm{g} / \mathrm{mL}$ solution. The solution was centrifuged for 10 minutes and an aliquot was diluted with water to obtain $200 \mu \mathrm{g} / \mathrm{mL}$. The final sample solution was prepared by mixing this solution with $400 \mu \mathrm{g} / \mathrm{mL}$ of IS solution (1:1 proportion), resulting in a solution with $100 \mu \mathrm{g} / \mathrm{mL}$ of empagliflozin and $200 \mu \mathrm{g} / \mathrm{mL}$ of IS.

\section{MEKC validation}

The proposed method was validated according to the ICH guidelines. The evaluated parameters were: specificity, linearity, precision, accuracy and robustness (ICH, 2005). A system suitability test was performed according to USP 39 (USP 39, 2016). 


\section{Specificity}

The stability-indicating capability of the method was evaluated by submitting the sample solution at $1000 \mu \mathrm{g} /$ $\mathrm{mL}$ to forced degradation conditions using oxidative, basic, acidic, photolytic and thermal conditions $(\mathrm{n}=2 /$ treatment).

To promote acidic and alkaline hydrolysis, $2 \mathrm{~mL}$ of empagliflozin sample solutions were mixed with $2 \mathrm{~mL}$ of $1 \mathrm{M} \mathrm{HCl} / 5$ hours or with to $2 \mathrm{~mL}$ of $2 \mathrm{M} \mathrm{NaOH} / 2$ hours and kept at room temperature. After the reaction time, the solutions were neutralized with $1 \mathrm{M} \mathrm{NaOH}$ or $1 \mathrm{M}$ $\mathrm{HCl}$, respectively. For the oxidative degradation, $2 \mathrm{~mL}$ of sample solution at $1000 \mu \mathrm{g} / \mathrm{mL}$ were exposed to $3 \%$ hydrogen peroxide for 10 days (240 hours). Photolytic degradation was carried out in a photostability chamber exposing the sample to UVA or UVC light. To perform it, $2 \mathrm{~mL}$ of the sample solution were placed in a covered disposable plastic cell for 48 hours or 5 hours, respectively. For thermal degradation, $2 \mathrm{~mL}$ of sample solution were exposed to heat $\left(40^{\circ} \mathrm{C}\right)$ for $48 \mathrm{~h}$ in a sealed glass container inside an oven.

After degradation treatment, the solutions were diluted in water to the concentration of $200 \mu \mathrm{g} / \mathrm{mL}$. Then, $1 \mathrm{~mL}$ of IS solution at $400 \mu \mathrm{g} / \mathrm{mL}$ and $1 \mathrm{~mL}$ of each degraded solution were mixed, reaching a theoretical final drug concentration of $100 \mu \mathrm{g} / \mathrm{mL}$ (empagliflozin) and 200 $\mu \mathrm{g} / \mathrm{mL}$ (paracetamol). It should be emphasized that even with the degradation, the drug concentration was within the method linearity range. The stability-indicating power of the method was suggested by the empagliflozin peak purity in the degraded samples using a PDA detector.

\section{Linearity}

Linearity was assessed by constructing three analytical curves, each one with five concentrations of empagliflozin standard in the range of 50 to $150 \mu \mathrm{g} / \mathrm{mL}$ $(50,75,100,125$ and $150 \mu \mathrm{g} / \mathrm{mL})$ and a fixed concentration of IS $(200 \mu \mathrm{g} / \mathrm{mL})$. The standard curves were obtained by plotting the ratio area (empagliflozin peak area/IS peak area) against empagliflozin concentration. The method of least square regression and analysis of variance was used to determine the MEKC method linearity $(\alpha=0.05)$.

\section{Accuracy}

Accuracy was verified through a recovery study. Sample solutions containing a fixed concentration of empagliflozin and IS were spiked with known amounts of empagliflozin standard solution at three different levels, aiming to obtain 80,100 and $120 \%$ of working concentration, i.e., 80,100 and $120 \mu \mathrm{g} / \mathrm{mL}$. The difference between the results obtained from the unspiked sample solution should correspond to the amount of drug added to the solution. This assay was performed in triplicate. Recovery values in the range of $100 \pm 2 \%$ of the target value were considered acceptable (ICH, 2005).

\section{Precision}

Sample solutions were prepared as described in the section "Standard and sample solutions preparation" and repeatability was assessed by the analysis of six independent samples prepared by a single analyst and on the same day. Intermediate precision was assessed by the preparation of other six independent samples on a second day. Values of relative standard deviation (RSD) $<2.0 \%$ were considered acceptable ( $\mathrm{ICH}, 2005)$.

\section{Robustness}

A full factorial $2^{3}$ design was performed in a random order. Intentional changes were made in the SDS concentration (45 and $55 \mathrm{mM}$, optimal $50 \mathrm{mM}$ ), buffer $\mathrm{pH}(9.7$ and 10.3, optimal 10.0) and voltage $(+27$ and +29 $\mathrm{kV}$, optimal $+28 \mathrm{kV}$ ) which were identified as critical parameters to the method reproducibility. To carry out this series of planned experiments, standard and sample solutions at the concentration of $100 \mu \mathrm{g} / \mathrm{mL}$ were used and the evaluated response was the empagliflozin assay. All experiments were performed in randomized order to minimize the effects of uncontrolled factors that could interfere in the response. The design of the experiment and the results were processed by Minitab ${ }^{\circledR} 17$ statistical software (Minitab State College, PA, USA).

As part of the robustness study, the stability of the standard solution was determined. Empagliflozin stock solutions $(1000 \mu \mathrm{g} / \mathrm{mL})$ were stored in a refrigerator $(5 \pm$ $3{ }^{\circ} \mathrm{C}$ ) and after 10 days, they were diluted and analyzed. The results were compared to freshly prepared solutions.

\section{System suitability test}

The system suitability test was performed to assure the resolution and the CE system reproducibility (USP $39,2016)$. It was evaluated by the analysis of six repeated injections of the standard solution prepared according to 
the section "Standard and sample solutions preparation". The evaluated factors were symmetry, theoretical plates, migration time and peak ratio.

\section{Degradation kinetic study}

The empagliflozin degradation rate in alkaline and acidic medium was studied as following: $3 \mathrm{~mL}$ of 1000 $\mu \mathrm{g} / \mathrm{mL}$ empagliflozin solution was added to $3 \mathrm{~mL}$ of 1 M sodium hydroxide solution or $1 \mathrm{M}$ hydrochloric acid. After 0, 72, 120, 144 and 192 hours of reaction, the solutions were neutralized as needed, diluted with water to an estimated concentration of $150 \mu \mathrm{g} / \mathrm{mL}$ and the residual content was analyzed by MEKC method. The kinetic of the degradation reaction was determined by the graphic method, plotting concentration versus time (zero order), In of concentration versus time (first order), and reciprocal of concentration versus time (second order). The correlation coefficient was calculated and the best fit was considered to establish the kinetic order. In addition, the half-life $\left(\mathrm{t}_{50 \%}\right)$ was calculated from the value of $\mathrm{k}$, and time for decomposition of 10\% $\left(\mathrm{t}_{90 \%}\right)$ (Yoshioka, Stella, 2002). Each degradation condition was evaluated in duplicate.

The drug degradation was also studied under stress conditions in oxidizing medium $\left(3 \% \mathrm{H}_{2} \mathrm{O}_{2}, 192 \mathrm{~h}\right)$, UVA light (365 nm, $192 \mathrm{~h})$ and heating $\left(40^{\circ} \mathrm{C}, 20\right.$ and 30 days).

\section{Cytotoxicity evaluation}

The cytotoxic effects of non-degraded and degraded samples were evaluated in $3 \mathrm{~T} 3$ cells (murine Swiss albino fibroblasts) by MTT viability assay, which is a measurement of cell metabolic activity and is based on the first described protocol (Mosmann, 1983). The degraded empagliflozin solutions were obtained from the exposure of the sample solutions to $1 \mathrm{mg} / \mathrm{mL}$ in the following conditions: alkaline medium $(1 \mathrm{M} \mathrm{NaOH})$, for 24 and 168 hours; acidic medium $(1 \mathrm{M} \mathrm{HCl})$, for 24 and 168 hours; UVA radiation ( $365 \mathrm{~nm}$ ), for 48 and 168 hours and UVC radiation ( $254 \mathrm{~nm}), 2$ and 10 hours. After the degradation procedure, the solutions were diluted to reach the theoretical empagliflozin concentration of 25,10 and $5 \mu \mathrm{g} / \mathrm{mL}$. Non-degraded samples of different concentrations $(25,10$ and $5 \mu \mathrm{g} / \mathrm{mL})$ were used as control for each respective degraded samples. The Cmax of empagliflozin after a single dose of $25 \mathrm{mg} /$ day is 687 $\mathrm{nmol} / \mathrm{L}$ (Package insert, Boehringer Ingelheim, 2016). Then, the smallest concentration used in the experiment was at least 16 times greater than the maximum plasmatic concentration expected.

The $3 \mathrm{~T} 3$ cell line was grown in DMEM medium supplemented with $10 \% \mathrm{FBS}(\mathrm{v} / \mathrm{v})$ at $37{ }^{\circ} \mathrm{C}, 5 \% \mathrm{CO}_{2}$. The cells were routinely cultured in $75 \mathrm{~cm}^{2}$ culture flasks and harvested using trypsin-EDTA when a confluence of about $80 \%$ was reached. Initially, the $3 \mathrm{~T} 3$ cells were seeded in the central 60 wells of a 96 well plate at a density of $1 \times 10^{5}$ cells $/ \mathrm{mL}$ and incubated for $24 \mathrm{~h}$ under $5 \% \mathrm{CO}_{2}$ at $3{ }^{\circ} \mathrm{C}$. After this period, the spent medium was replaced by $100 \mu \mathrm{L}$ of fresh medium supplemented with $5 \% \mathrm{FBS}(\mathrm{v} / \mathrm{v})$ containing the non-degraded or degraded samples. The control cells were treated only with medium (containing 5\% FBS, v/v). The cells were exposed to each treatment for $24 \mathrm{~h}$. After, the medium containing the samples was removed followed by the addition of $100 \mu \mathrm{L}$ of MTT tetrazolium salt $(500 \mu \mathrm{g} /$ $\mathrm{mL}$ dissolved in FBS-free medium) to each well. Plates were further incubated for $3 \mathrm{~h}$ to allow the formation of purple formazan crystals. Thereafter, these crystals were solubilized by the addition of $100 \mu \mathrm{L}$ of DMSO to each well followed by stirring for $10 \mathrm{~min}$ at room temperature. The solutions absorbance was measured at $550 \mathrm{~nm}$ in a microplate reader, model SpectraMax M2 (Molecular Devices, Sunnyvale, CA). Each sample cytotoxicity was expressed as percentage of viability regarding untreated control cells (the mean optical density of untreated cells was set at $100 \%$ viability).

\section{Statistical analysis}

The experimental design and the statistical analysis of the robustness test were carried out on Minitab ${ }^{\circledR} 17$ statistical software (Minitab State College, PA, USA). Statistical analysis of the cytotoxicity assays were performed using one-way analysis of variance (ANOVA) with SPSS ${ }^{\circledR}$ v. 22 software (SPSS Inc., Chicago, IL, USA), followed by Dunnett post-hoc analysis.

\section{RESULTS AND DISCUSSION}

\section{Method optimization}

Due to its pka value (12.57), empagliflozin is not ionized in the common $\mathrm{pH}$ range used in capillary zone electrophoresis, the simplest technique used in CE. Thus, a micellar electrokinetic chromatography (MEKC) method was developed because of its ability to separate both neutral and charged molecules (Harstad et al., 
2016; Terabe, 2010). Several conditions were tested with two buffer solutions (boric acid or TRIS) in different concentrations $(10-30 \mathrm{mM})$ in a wide $\mathrm{pH}$ range (5.5-10), mixed with sodium dodecylsulfate (SDS), tested at two concentrations (80 and $100 \mathrm{mM}$ ). To define optimal conditions, migration time, peak symmetry, area, shape and resolution among the peaks of analyte internal standard were the evaluated parameters.

In all the analytical conditions, boric acid was associated to high currents, which lead to capillary breakage. Then, TRIS was used because it has characteristics of a biological buffer with large ions of low mobility, which can be used in high concentrations without causing excessive heat to the capillary, and consequently it does not generate high currents to the equipment (Gomori, 1955; Harstad et al., 2016). In agreement to the literature (Vinther, Soeberg, 1991; Rizvi, Do, Saleh, 2011), it was observed that high surfactant concentration was associated with better symmetry values and reduced the migration time. Changes in temperature $\left(25^{\circ} \mathrm{C}-30^{\circ} \mathrm{C}\right)$ and voltage $(+20 \mathrm{kV}$ to $+28 \mathrm{kV}$ ) were performed, and it was observed that higher values were related to the decrease in the migration time of the analytes. Concerning the internal standard, paracetamol was chosen because it is an acidic drug as empagliflozin, with appropriate resolution between both peaks and produced a detector response similar to that produced by the analyte.

This way, the test results indicated that the following analytical conditions induced adequate analytical response, which was defined for the analysis of the empagliflozin: running electrolyte composed of $20 \mathrm{mM}$ TRIS buffer, $\mathrm{pH}$ 10: $100 \mathrm{mM}$ SDS (1:1 v/v); paracetamol as internal standard; voltage $+28 \mathrm{kV}$, which produced current values between 20 and $22 \mu \mathrm{A} ; 28^{\circ} \mathrm{C}$ temperature; hydrodynamic injection of $4 \mathrm{~s}(50 \mathrm{mBar})$ and wavelength detection at $225 \mathrm{~nm}$. Under these conditions, the analyte and internal standard peaks showed adequate symmetry (1.0 and 1.1, respectively), appropriate resolution (17.8) and migration time at about 4 and 2 minutes (empagliflozin and paracetamol, respectively).

\section{Method validation}

\section{Specificity}

Forced degradation assays were performed to evaluate the method ability to quantify empagliflozin in the presence of excipients and degradation products.
Stress testing should result in at least 5-20\% degradation and the complete sample degradation should be avoided (Alsante et al., 2007; Brasil, 2015). Therefore, preliminary tests were performed to define the degradation conditions. Peak purity was evaluated by DAD equipped with CE. Empagliflozin was degraded in alkaline and acidic medium obtaining residual contents of $80.44 \%$ and $84.31 \%$, respectively $(2 \mathrm{M} \mathrm{NaOH} / 2$ hours and $1 \mathrm{M} \mathrm{HCl} / 5$ hours). However, no additional peaks were observed (electropherograms not shown). Under UVA and UVC radiation, after 48 and 5 hours of exposure, respectively, the residual content was $88.36 \%$ and $76.06 \%$, and additional peaks of degradation products were observed (UVA-3.6 minutes and UVC-3.9 and 4.3 minutes) (Figure 1). Under heating, after 48 hours at $40{ }^{\circ} \mathrm{C}$, the empagliflozin content decreased to $90.01 \%$ without additional degradation peaks (electropherograms not shown). In the oxidizing medium, the degradation was evaluated during 10 days and a residual content around $92.3 \%$ was obtained. In all degradation conditions, the empagliflozin peaks present a peak purity index $>$ 0.99 , what indicated that comigration with degradation products did not occurred. Besides, the resolution between empagliflozin and the nearest degradation product (DP2, Figure 1-D) was 2.68 ( $\mathrm{RSD}=2.54)$. This set of results confirms the method specificity.

It is important to emphasize that, although empagliflozin was degraded in alkaline medium, this effect was not evident during the analysis, where a running electrolyte with $\mathrm{pH} 10$ was used. This was indicated by several analyses performed during the method optimization where different $\mathrm{pH}$ values were employed (5.5 to 10) and similar results (\% empagliflozin assay) were obtained. Besides, in the specificity test we observed that the degradation occurred only after longer reaction times and when a stronger reagent was used (2 $\mathrm{M} \mathrm{NaOH}, \mathrm{pH}>13)$.

\section{Linearity}

The ratio between peak areas versus concentration resulted in a linear regression with a correlation coefficient of $\mathrm{r}=0.9999$ and linear equation $\mathrm{y}=0.0165 \mathrm{x}-0.0558$, where $\mathrm{x}$ is the concentration and $\mathrm{y}$ is the area ratio. According to the statistical analysis performed by ANOVA, it showed a significant linear regression $(\mathrm{p}<0.05)$ and non-significant linear deviation ( $p>0.05)$. Therefore, the analytical curve for empagliflozin was considered linear in the range of $50-150 \mu \mathrm{g} / \mathrm{mL}$. 


\section{Precision}

The repeatability (intra-day assay) was evaluated by the analysis of six samples, on the same day and by the same analyst, and the mean assay was $98.63 \pm 0.78$ (RSD $=0.79 \%$ ). The intermediate precision (inter-day assay) was assessed by the analyses of other six independent samples by a different analyst, which showed a mean assay of $99.08 \% \pm 0.92(\mathrm{RSD}=0.93 \%)$. Both repeatability and intermediate precision levels showed low RSD values $(<2 \%)$ confirming the method precision. These results also indicated that the mean of the assay $(98.86 \pm 0.84$, $\mathrm{RSD}=0.85 \%, \mathrm{n}=12$ ) was in agreement with the label claim for empagliflozin tablets.

\section{Accuracy}

The mean recovery was $100.60 \%$ with RSD $0.60 \%$, indicating that it was within the established recovery range (98-102\%) and confirming the method accuracy (Table I).

TABLE I - Recovery results for MEKC method

\begin{tabular}{cccc}
\hline Standard solution $(\boldsymbol{\mu g} / \mathbf{m L})$ & $\begin{array}{c}\text { Recovery } \\
\mathbf{( \% )}^{\mathbf{a}}\end{array}$ & $\begin{array}{c}\text { Mean } \\
\text { recovery } \\
\mathbf{( \% )}^{\mathbf{b}}\end{array}$ \\
\hline 30 & $30.03 \pm 0.09$ & $100.10 \pm 0.28$ & $100.6 \pm 0.60$ \\
\hline 50 & $50.20 \pm 0.19$ & $100.40 \pm 0.38$ & \\
\hline 70 & $70.91 \pm 0.16$ & $101.30 \pm 0.22$ & \\
\hline
\end{tabular}

${ }^{\mathrm{a}}$ mean of three replicates $\pm \mathrm{SD}$; ${ }^{\mathrm{b}}$ mean of all recovery data \pm $\mathrm{SD}(\mathrm{n}=9)$

\section{Robustness}

The robustness was evaluated by a factorial $2^{3}$ design, in duplicate, in a random order, using the Minitab $^{\circledR} 17$ statistical program. The factors commonly studied in capillary electrophoresis include $\mathrm{pH}$ and composition of buffer or running electrolyte, applied voltage, capillary length, temperature and other characteristics (Dejaegher, Heyden, 2007). We evaluated the voltage effect, temperature and surfactant concentration because during preliminary tests for the method development they demonstrated great influence on results.

It was observed small variations in the empagliflozin assay, as well as in the peak symmetry and migration time. Values of peak symmetry ranged from 1.0 to 1.13 ; empagliflozin migration time from 3.7 to 4.58 , and assay from $99.04 \%$ to $100.86 \%$. The significance of the factors was evaluated through Pareto chart (Figure 2), which consists of bars with a proportional length to the absolute value of the estimated effect, divided by the pseudo standard error defined by Lenth (Lenth's PSE) (Lenth, 1989). The codes A, B and C correspond to the evaluated factors, voltage, buffer $\mathrm{pH}$ and surfactant concentration. When an interaction among two or more factors happens, a bar with this combination is indicated. From these results, it was concluded that none of the factors or combinations of factors produced significant changes in the results, indicating the developed method robustness.

The stability of the standard stock solution (1000 $\mu \mathrm{g} / \mathrm{mL}$ ), stored under refrigeration, was evaluated by the assay against a freshly prepared solution. The assay of the 10-day-old empagliflozin stored in a refrigerator was $99.6 \%$. However, the assay on the $23^{\text {rd }}$ day gave an empagliflozin content of $95.8 \%$, indicating that degradation occurred. Then, a stability of 10 days can be suggested.

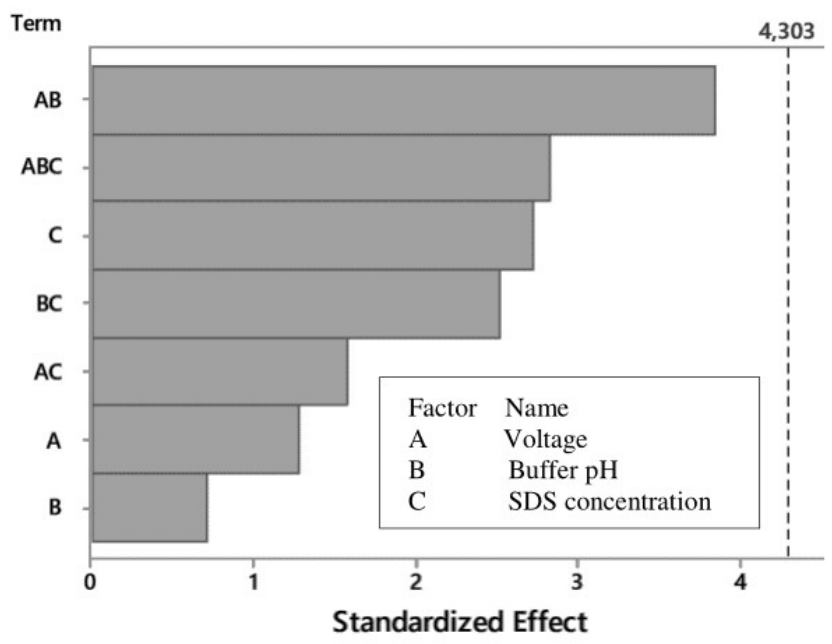

FIGURE 2 - Pareto plot of standardized effects (response is assay; $\alpha=0.05$ ).

\section{System suitability test}

The system suitability was assessed through six repeated injections of the standard solution at a 
concentration of $100 \mu \mathrm{g} / \mathrm{mL}$. The evaluated parameters of the empagliflozin peak were migration time, 4.33 $(\mathrm{RSD}=0.98 \%)$, symmetry, $0.97(\mathrm{RSD}=2.58 \%)$, theoretical plates, $33143(\mathrm{RSD}=4.87 \%)$, resolution $27.64(\mathrm{RSD}=1.79 \%)$, capacity factor $1.64(\mathrm{RSD}=0.75 \%)$ and peak area ratio, $1.62(\mathrm{RSD}=0.88 \%)$. The lower RSD values indicated the suitability of the EC system.

\section{Degradation kinetic study}

The stability of empagliflozin solutions was studied observing the following conditions: alkaline, acid and oxidant media, radiation (UVA) and temperature $\left(40^{\circ} \mathrm{C}\right)$. As shown in Figure 3, the degradation is more intense in alkaline and acid media. In these conditions, empagliflozin degradation reached $>50 \%$ after an 8 -day reaction. The degradation follows first order kinetics for both tested conditions, since there is a linear relation between the logarithm of the residual concentration versus time $(\mathrm{r}=0.9893$ in alkaline medium and $\mathrm{r}=0.9859$ in acidic medium). The rate constant order (k) was determined and the values obtained were 0.004292 and 0.004171 (alkaline and acidic media, respectively). From this data, the $\mathrm{t}_{90 \%}$ (time for $10 \%$ decomposition) and the $\mathrm{t}_{50 \%}$ (time for $50 \%$ decomposition) were calculated. In alkaline condition it was obtained the following values $\mathrm{t}_{90 \%}=24.7 \mathrm{~h}$ and $\mathrm{t}_{50 \%}=161.5 \mathrm{~h}$ and in acidic medium the values were $\mathrm{t}_{90 \%}=25.4 \mathrm{~h}$ and $\mathrm{t}_{50 \%}=166.1 \mathrm{~h}$.

The 8-day exposure to the oxidant medium reduced the empagliflozin content to $93.2 \pm 0.97 \%$ and under UVA radiation, the content reduced to $70.1 \% \pm 1.75 \%$. At $40{ }^{\circ} \mathrm{C}$ the degradation was slower and after 30 days, the empagliflozin content reached $77.52 \pm 1.73 \%$. In these three conditions the degradation kinetic was not determined, since the drug content did not reached values $<50 \%$, which is the recommended value to calculate the degradation parameters (Lachman, Deluca, Akers, 2001).

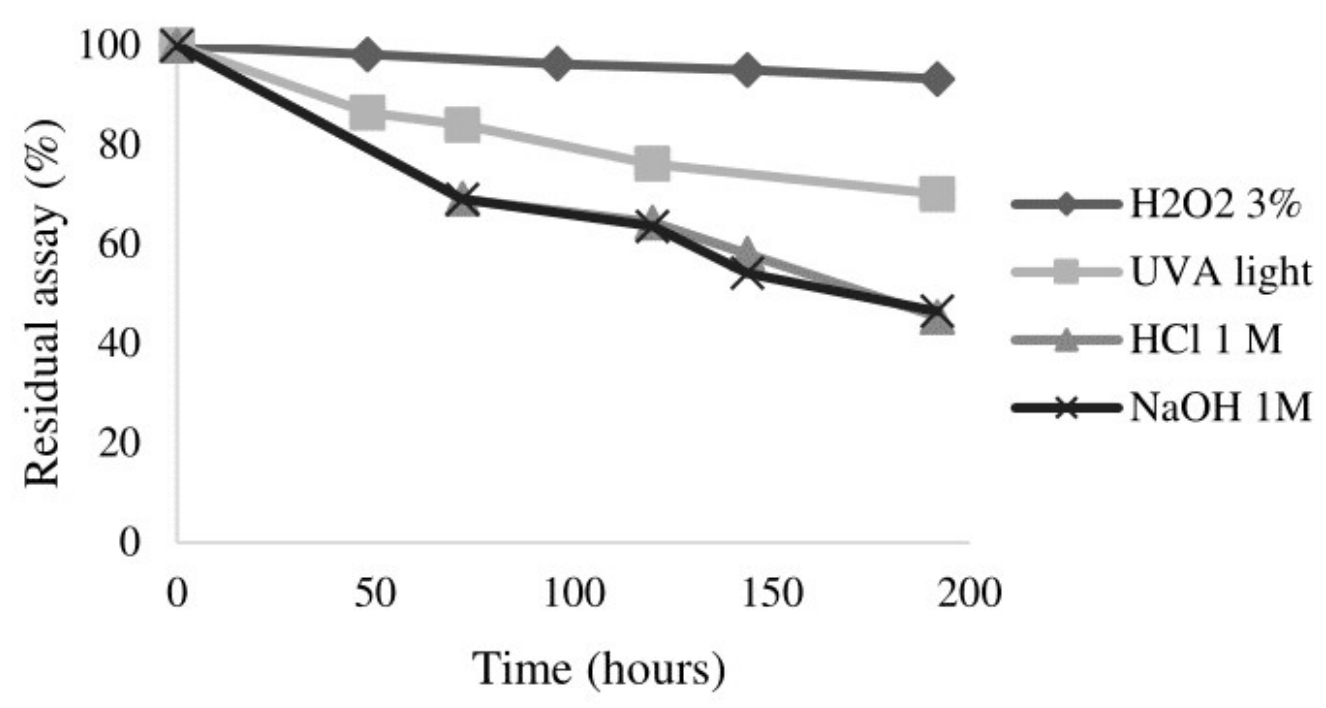

FIGURE 3 - Empagliflozin solutions stability on stress test evaluated on an 8-day period.

\section{Cytotoxicity evaluation}

The effect of non-degraded and degraded empagliflozin samples on the cellular viability of 3T3 cells was evaluated by MTT viability assay. The empagliflozin degradation was achieved by the exposure of sample solutions to alkaline medium, acidic medium, UVA and
UVC radiation. Two reaction times in each degradation procedure were used aiming to obtain different amounts of degradation products. Non-degraded samples at 25, 10 and $5 \mu \mathrm{g} / \mathrm{mL}$ were prepared and used as control for each tested concentration. Figure 4 shows the average cell viability (\%).

All solutions, including the non-degraded samples, presented a slight cytotoxicity. Sample solutions exposed 
for 10 hours to UVC radiation, in the concentration of 25 or $10 \mu \mathrm{g} / \mathrm{mL}$ decreased the cell viability, as well as the solutions obtained by alkaline hydrolysis at $10 \mu \mathrm{g} /$ $\mathrm{mL}(\mathrm{p}<0.05)$. The cell viability was not affected by the solutions containing greater levels of degradation products, demonstrating that no significant differences were observed between the two exposition times.

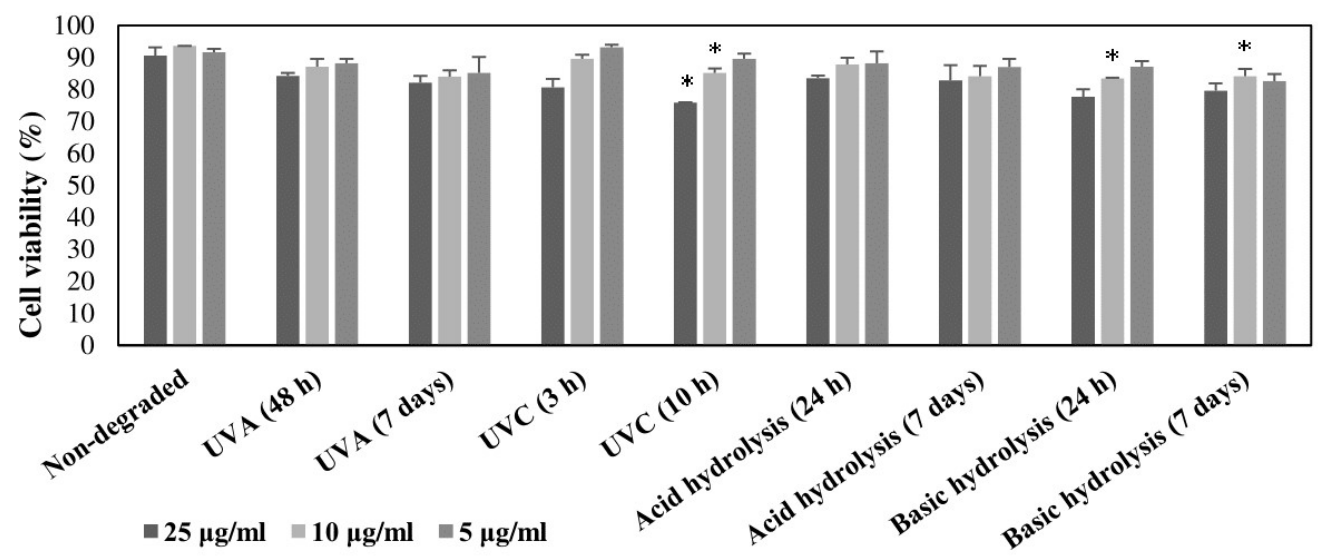

FIGURE 4 - Mean cell viabilities (\%) of degraded samples analyzed in two different times and three concentrations, using 3T3 cells and MTT assay. *significant response compared to the respective non-degraded sample $(\mathrm{p}<0.05)$.

\section{CONCLUSION}

The method proposed by MEKC is the first stabilityindicating method by capillary electrophoresis developed for the analysis of empagliflozin tablets. It met the ICH requirements being specific, linear, precise, accurate, robust, simple and environmentally friendly. Thus, it can be used in quality control analysis as well as in stability studies. The forced degradation study indicated that empagliflozin degradation occurred only after several hours of reaction and with the use of strong reagents, suggesting its high intrinsic stability. The in vitro cytotoxicity assay demonstrated that most of the degraded sample solutions induced no cytotoxic effect under the studied conditions.

\section{ACKNOWLEDGEMENTS}

Pauline Trindade Biscaino and Ana Paula Christ are thankful for their research fellowships to Conselho Nacional de Desenvolvimento Científico e Tecnológico (CNPq) and Coordenação de Aperfeiçoamento de Pessoal de Nível Superior - Brasil (CAPES) - Finance Code 001.

\section{REFERENCES}

Alsante KM, Ando A, Brown R, Ensing J, Hatajik TD, Kong W, Tsuda Y. The role of degradant profiling in active pharmaceutical ingredients and drug products. Adv Drug Deliv Rev. 2007;59(1):29-37.

Altria K, Marsh A, Griend CS. Capillary electrophoresis for the analysis of small-molecule pharmaceuticals. Electrophoresis. 2006;27(12):2263-2282.

Ayoub BM. UPLC simultaneous determination of empagliflozin, linagliptin and metformin. RSC Adv. 2015;5(116):95703-95709.

Ayoub BM. Development and validation of simple spectrophotometric and chemometric methods for simultaneous determination of empagliflozin and metformin: Applied to recently approved pharmaceutical formulation. Spectrochim Acta A Mol Biomol Spectrosc. 2016;168:118-122.

Ayoub BM. Green pharmaceutical analysis of drugs coformulated with highly different concentrations using spiking and manipulation of their ratio spectra. J AOAC Int. 2017;100(4):985-991.

Ayoub BM, Mowaka S. LC-MS/MS determination of empagliflozin and metformin. J Chromatogr Sci. 2017;55(7):742-747.

Barden AT, Piccoli BL, Volpato NM, Steppe M. A simultaneous assay method using capillary zone electrophoresis for a fixed dose combination of vildagliptin and metformin hydrochloride in coated tablets. Anal Methods. 2013;(20):5701-5708.

Brasil. Agência Nacional de Vigilância Sanitária. RDC $\mathrm{n}^{\circ}$ 53 de 04 de dezembro de 2015. Parâmetros para notificação, 
Pauline Trindade Biscaino; Ana Paula Christ; Daniele Rubert Nogueira Librelotto; Clarice Madalena Bueno Rolim; Andréa Inês Horn Adams

identificação e qualificação de produtos de degradação em medicamentos com substâncias ativas sintéticas e semissintéticas, classificados como novos, genéricos e similares, e dá outras providências. Diário Oficial da União; Poder executivo, 04 de dezembro de 2015.

Cersosimo E, Herrera-Solis C, Triplitt C. Inhibition of renal glucose reabsorption as a novel treatment for diabetes patients. J Braz Nephrol. 2014;36(1):80-92.

Dejaegher B, Heyden YV. Ruggedness and robustness testing. J Chromatogr A. 2007;1158(1-2):138-157.

Geetha PS, Lakshmana KR, Prasad KRS, Suresh KB. Development and validation of stability indicating reversed phase high-pressure liquid chromatography method for simultaneous estimation of metformin and empagliflozin in bulk and tablet dosage form. Asian J Pharm Clin Res. 2016;9(1):126-135.

Ghany-Abdel MF, Aziz-Abdel O, Ayad MF, Tadros MM. New LC-UV methods for pharmaceutical analysis of novel antidiabetic combinations. Acta Chromatogr. 2017;29(4):448-452.

Gomori G. Preparation of Buffers for Use in Enzyme Studies. Methods Enzymol. 1955;1:138-146.

Gopal NM, Sridhar C. A validated stability indicating ultra-performance liquid chromatographic method for simultaneous determination of metformin hydrochloride and empagliflozin in bulk drug and tablet dosage form. Int J App Pharm. 2017;9(3):45-50.

Hancu G, Simon B, Rusul A, Mircia E, Gyéresil Á. Principles of Micellar Electrokinetic Capillary Chromatography Applied in Pharmaceutical Analysis. Adv Pharm Bull. 2013;3(1):1-8.

Harstad RK, Johnson AC, Weisenberger MM, Bowser MT. Capillary Electrophoresis. Anal Chem. 2016;88(1):299-319.

ICH. International Conference on Harmonisation of Technical Requeriments for Registration of Pharmaceuticals for Human Use. ICH Harmonised Tripartite Guideline: Harmonised Tripartite Guideline: Guideline on Validation of Analytical Procedure-Q2 (R1). 2005.

Jojima T, Tomotsune T, Lijima T, Akimoto K, Suzuki K, Aso Y. Empagliflozin (an SGLT2 inhibitor), alone or in combination with linagliptin (a DPP-4 inhibitor), prevents steatohepatitis in a novel mouse model of non-alcoholic steatohepatitis and diabetes. Diabetes Metab Syndr. 2016;8(45):1-11.

Lachman L, Deluca P, Akers MJ. Testes de estabilidade e fundamentos de cinética química. In: Lachman L; Lieberman HA; Kanig JL. Teoria e prática na indústria farmacêutica, Lisboa: Calouste Gulbenkian, 2001.
Milech A, et al., Oliveira JEP, Vencio S, organizadores. Diretrizes da Sociedade Brasileira de Diabetes. São Paulo: A.C. Farmacêutica; 2016.

Lenth RV. Quick and easy analysis of unreplicated factorials. Technometrics. 1983;31(4):469-473.

Mosmann T. Rapid colorimetric assay to cellular growth and survival: application to proliferation and cytotoxicity assays. J Immunol Methods. 1983;65(1-2):55-63.

Padmaja N, Veerabhadram G. Development and validation of analytical method for Simultaneous estimation of Empagliflozin and Linagliptin in bulk drugs and combined dosage forms using UV-visible spectroscopy. Pharm Lett. 2015;7(12):306-312.

Padmaja N, Veerabhadram G. Method development and validation of RP-HPLC method for the estimation of empagliflozin in API. Int J Pharm Sci Res. 2016;7(2):724-727.

Padmaja N, Veerabhadram G. A Novel Stability Indicating RP-UPLC-DAD Method for Determination of Metformin and Empagliflozin in Bulk and Tablet Dosage form. Oriental J Chemistry. 2017;33(4):1949-1958.

Package insert. Jardiance ${ }^{\circledR}$ (empagliflozin). Boehringer Ingelheim. 2016.

Rizvi SAA, Do DP, Saleh AM. Fundamentals of micellar electrokinetic chromatography (MEKC). Eur J Chem. 2011;2(2):276-281.

Shyamala K, Nirmala J, Mounika J, Nandini B. Validated stability-indicating RP-HPLC method for determination of empagliflozin. Pharm Lett. 2016;8(2):457-464.

Terabe S. Twenty-five years of micellar electrokinetic chromatography. Procedia Chem. 2010;2:2-8.

USP 39. Ed. United States Pharmacopeial Convention: Rockville, United States of America, 2016.

Vinther A, Soeberg H. Temperature elevations of the sample zone in free solution capillary electrophoresis under stacking conditions. J Chromatogr A. 1991;559(1-2):27-42.

Watson DG. Pharmaceutical Analysis. A Textbook for pharmacy students and pharmaceutical chemists. Edinburgh: Elsevier Churchill Livingstone, 2005.

Yoshioka S, Stella V J. Stability of Drugs and Dosage Forms, New York, 2002.

Received for publication on $26^{\text {th }}$ October 2018 Accepted for publication on $29^{\text {th }}$ September 2019 